\title{
Analysis of the Foreign Trade and Gross Domestic Product Effect on Foreign Direct Investment using Panel Data Regression Estimation
}

\author{
Winda P. Anggraini ${ }^{a}$ \\ ${ }^{a}$ Politeknik Statistika STIS. Email: windaputri.anggraini@yahoo.com
}

\section{A B S TRACT}

\begin{abstract}
Investment is one of the components that determines a country's economic growth. Sources of investment funds can be seen through two approaches, domestic investment and foreign investment. One of the promising components of foreign investment is Foreign Direct Investment (FDI). FDI is considered more valuable for the country because it is more long-term in nature. This study aims to see the effect of Gross Domestic Product (GDP) and export-import as foreign trade activities on FDI, through estimation with panel data regression model. The data used is data from 20 countries with observation period from 2009 to 2018. With the Random Effect Model as the best model, which the estimators also qualify the BLUE estimator. it can be concluded that partially the GDP variable has no significant effect. Meanwhile, exports have a significant positive effect and imports have a significant negative effect on FDI.
\end{abstract}

Keywords: Foreign Direct Investment, Panel Data Regression, Random Effect Model.

\section{A B S T R A K}

Investasi merupakan salah satu komponen yang menentukan pertumbuhan ekonomi suatu negara. Sumber dana investasi dapat dilihat melalui dua pendekatan, yaitu dalam negeri dan asing. Salah satu komponen investasi asing yang menjanjikan adalah Foreign Direct Investment (FDI). FDI dianggap lebih bernilai bagi negara karena lebih bersifat jangka panjang. Penelitian ini bertujuan untuk melihat pengaruh Gross Domestic Product (GDP) dan ekspor-impor sebagai kegiatan perdagangan luar negeri terhadap FDI melalui estimasi model regresi data panel terbaik. Data yang digunakan adalah data 20 negara dengan periode pengamatan 2009 sampai dengan 2018. Dengan Random Effect Model sebagai model terbaik, dimana estimator yang dihasilkan juga telah memenuhi sifat BLUE, didapatkan kesimpulan bahwa secara parsial variabel GDP tidak berpengaruh signifikan. Sedangkan, ekspor berpengaruh signifikan positif dan impor berpengaruh signifikan negatif terhadap FDI.

Kata Kunci: Foreign Direct Investment, Regresi Data Panel, Random Effect Model

Diserahkan: 04-11-2020; Diterima: 09-07-2021;

Doi: https://doi.org/10.29303/emj.v4i1.85

* Corresponding author.

Alamat e-mail: windaputri.anggraini@yahoo.com 


\section{Pendahuluan}

Kegiatan perdagangan luar negeri memiliki peranan yang cukup penting dalam menggerakan roda perekonomian suatu negara. Salvatore (2007) menyatakan bahwa kegiatan perdagangan luar negeri tidak selalu menguntungkan, sehingga harus ada alternatif lain untuk mendukung pertumbuhan ekonomi suatu negara, salah satu upaya yang dapat dilakukan adalah meningkatkan investasi.

Sumber dana investasi dapat dilihat melalui dua pendekatan, yaitu dalam negeri dan asing. Investasi asing sangat diperlukan untuk pembiayaan program percepatan pembangunan nasional. Di sisi lain, tingkat pertumbuhan ekonomi sangat menentukan perkembangan investasi asing. Investor asing cenderung lebih tertarik menanamkan investasinya jika tingkat pertumbuhan ekonomi pada suatu negara tertentu dinilai baik dan menjanjikan. Investasi asing sendiri dibagi menjadi tiga, yaitu portofolio, Foreign Direct Investment (FDI), dan kredit ekspor. FDI dianggap lebih bernilai bagi negara dibandingkan investasi pada ekuitas perusahaan karena FDI lebih bersifat jangka panjang, sedangkan investasi ekuitas lebih bersifat jangka pendek dan sewaktu-waktu dapat menimbulkan kerentanan ekonomi.

\section{Tinjauan Pustaka}

\subsection{Foreign Direct Investment}

Menurut Todaro \& Smith (2003), Foreign Direct Investment merupakan investasi yang dilakukan oleh pihak swasta asing, yang mana dana-dana investasinya langsung digunakan untuk menjalankan kegiatan bisnis seperti mendatangkan mesin-mesin dan membeli bahan baku produksi. Teori elektikal Dunning (1993) menyatakan bahwa keunggulan yang harus dimiliki oleh suatu negara untuk menarik investasi asing antara lain yaitu rendahnya biaya produksi, tersedianya pasar yang besar, ketersediaan sumber daya, minimnya hambatan perdagangan, dan tingkat keterbukaan ekonomi.

\subsection{Ekspor}

Ekspor adalah semua barang dan jasa yang dijual kepada penduduk negara lain, ditambah dengan jasajasa yang diselenggarakan kepada penduduk negara tersebut berupa pengangkutan permodalan dan halhal lain yang membantu kegiatan ekspor tersebut (Winardi, 1992). Kegiatan ekspor dilandasi atas kesadaran bahwa setiap negara di dunia ini tidak ada yang benar-benar bisa mandiri dan saling membutuhkan satu sama lainnya. Suatu negara melakukan ekspor produksinya ke negara lain yang membutuhkan produk tertentu dan tidak dapat memenuhi kebutuhan akan produk tersebut. Semakin tinggi aktivitas ekspor suatu negara maka iklim investasi dan pertumbuhan ekonominya juga semakin baik.

\subsection{Impor}

Menurut Departemen Koperasi Indonesia, impor adalah kegiatan mendatangkan barang/jasa dari luar negeri untuk memenuhi keperluan produksi dalam negeri. Impor memiliki pengaruh negatif bagi sejumlah negara karena dalam hal ini impor berarti mengeluarkan sejumlah dana untuk memenuhi kebutuhan. Dengan kata lain, kebutuhan dalam negeri belum mampu dipenuhi oleh produksi domestik. Semakin tinggi jumlah impor, maka akan mengurangi kepercayaan para investor untuk menanamkan modalnya bagi negara tersebut.

\subsection{Gross Domestic Product}

Gross Domestic Product atau GDP adalah jumlah produksi berupa barang dan jasa yang dihasilkan di suatu daerah tertentu yang dapat dijadikan sebagai tolak ukur pertumbuhan ekonomi dari sebuah negara. Dengan kata lain, GDP dapat dijadikan salah satu indikator perekonomian sebuah negara. Hubungan investasi asing dengan tingkat GDP dapat diinterpretasikan bahwa kalau GDP suatu negara meningkat maka akan berdampak pada meningkatnya investasi di negara tersebut dan berlaku sebaliknya.

\section{Metode}

\subsection{Data dan Sumber Data}

Data yang digunakan merupakan data sekunder bersumber dari situs World Bank. Data yang digunakan dalam penelitian ini berupa data panel dengan jumlah observasi sebanyak 20 negara dengan periode waktu tahun 2009 sampai dengan 2018. Variabel dependen yang digunakan adalah Foreign Direct Investment (FDI), dengan variabel independen adalah Gross Domestic Product (GDP), ekspor (X), dan impor (M).

\subsection{Uji Stasioneritas}

Uji stasioneritas digunakan untuk menguji apakah setiap variabel yang digunakan dalam penelitian telah stasioner, pengujian dilakukan dengan melihat keberadaan panel unit root pada series yang 
digunakan. Pengujian stasioneritas dilakukan dengan mengunakan Levin, Lin, and Chu (LLC) Test:

$$
\Delta y_{i t}=\rho y_{i, t-1}+\sum \theta_{i t} \Delta y_{i t-j}+X_{i t}^{*} \delta+\varepsilon_{i t}
$$

dengan hipotesis sebagai berikut.

$$
\begin{aligned}
& H_{0}: \quad \theta_{i}=0 \text { for all } i \\
& H_{1}: \quad \theta<0 \text { (each series are stasionary as a panel) }
\end{aligned}
$$

Jika $p$-value yang dihasilkan dari uji LLC kurang dari nilai $\alpha$ sebesar 5\%, maka akan tolak Ho atau dengan kata lain data dapat disimpulkan telah stasioner.

\subsection{Regresi Data Panel}

Persamaan data panel yang merupakan gabungan dari data cross section dan data time series adalah sebagai berikut:

$$
F D I_{i t}=\beta_{0}+\beta_{1} G D P_{i t}+\beta_{2} X_{i t}+\beta_{3} M_{i t}+\varepsilon_{i t}
$$

dengan,

$$
\begin{aligned}
i= & 1,2, \ldots, 20 \\
t= & 1,2, \ldots, 10 \\
\varepsilon_{i t}= & U_{i}+V_{i t} \\
U_{i}= & \text { efek individu ke- } i \\
V_{i t}= & \text { efek interaksi antara efek individu dan efek } \\
& \text { waktu secara bersamaan }
\end{aligned}
$$

\section{- Common Effect Model}

Common Effect mengabaikan adanya perbedaan dimensi individu maupun waktu atau dengan kata lain perilaku data antar individu sama dalam berbagai kurun waktu.

$$
\begin{aligned}
F D I_{i t}= & \beta_{0}+\beta_{1} G D P_{i t}+\beta_{2} X_{i t}+\beta_{3} M_{i t}+ \\
& V_{i t}
\end{aligned}
$$

\section{- Fixed Effect Model}

Fixed Effect mengasumsikan bahwa intersep dari setiap individu adalah berbeda sedangkan slope antar individu adalah tetap (sama).

$$
\begin{gathered}
F D I_{i t}=\left[\beta_{0}+U_{i}\right]+\beta_{1} G D P_{i t}+\beta_{2} X_{i t}+ \\
\beta_{3} M_{i t}+V_{i t}
\end{gathered}
$$

\section{- Random Effect Model}

Random Effect mengasumsikan setiap individu mempunyai perbedaan intersep, yang mana intersep tersebut adalah variabel random atau stokastik.

$$
\begin{aligned}
F D I_{i t}= & \beta_{0}+\beta_{1} G D P_{i t}+\beta_{2} X_{i t}+\beta_{3} M_{i t}+ \\
& {\left[U_{i}+V_{i t}\right] }
\end{aligned}
$$

\subsection{Pemilihan Model Terbaik}

Berikut diberikan penjelasan mengenai pengujian yang dilakukan.

- Chow Test

Chow Test digunakan untuk mengetahui apakah terdapat efek individu pada data panel yang akan dimodelkan. Kesimpulan Chow Test dapat juga digunakan untuk memilih model regresi yang lebih baik antara Fixed Effect Model dan Common Effect Model. Hipotesis pengujian adalah sebagai berikut.

$$
\begin{aligned}
& H_{0}: U_{1}=U_{2}=\ldots \ldots=U_{i}=0 ; i=1,2, \ldots, 20 \\
& H_{1}: \text { Minimal terdapat satu Ui yang } \neq 0
\end{aligned}
$$

Jika $p$-value yang dihasilkan kurang dari nilai $\alpha$ sebesar 0,05 maka akan tolak $\mathrm{H}_{0}$, sehingga dikatakan bahwa Fixed Effect Model lebih baik daripada Common Effect Model.

\section{- Hausmann Test}

Haussman Test digunakan untuk mengetahui apakah efek individu yang ada pada data panel bersifat random atau fixed. Kesimpulan Haussman Test dapat juga digunakan untuk memilih model regresi yang lebih baik antara Fixed Effect Model dan Random Effect Model. Hipotesis pengujian adalah sebagai berikut:

$$
\begin{aligned}
& H_{0}: E\left(u_{i} \mid G D P_{i t}, X_{i t}, M_{i t}\right)=0 \\
& H_{l}: E\left(u_{i} \mid G D P_{i t}, X_{i t}, M_{i t}\right) \neq 0
\end{aligned}
$$

Jika $p$-value yang dihasilkan kurang dari nilai $\alpha$ sebesar 0,05 maka akan tolak $\mathrm{H}_{0}$ sehingga dikatakan bahwa Fixed Effect Model lebih baik daripada Random Effect Model.

\section{- Breush-Pagan Lagrange Multiplier}

Uji Breush-Pagan Lagrange Multiplier dapat digunakan untuk mengetahui apakah model Random Effect lebih baik dari model Common Effect. Hipotesis pengujian adalah sebagai berikut:

$$
\begin{aligned}
& H_{0}:{\sigma_{u_{i}}}^{2}=0 \\
& H_{l}: \sigma_{u_{i}}{ }^{2} \neq 0
\end{aligned}
$$


Jika $p$-value yang dihasilkan kurang dari nilai $\alpha$ sebesar 0,05 maka akan tolak $\mathrm{H}_{0}$ sehingga dikatakan bahwa Random Effect Model adalah model terbaik.

\section{Hasil dan Pembahasan}

\subsection{Uji Stasioneritas}

Uji stasioneritas digunakan untuk menguji apakah setiap variabel yang digunakan dalam penelitian telah stasioner, pengujian dilakukan dengan melihat keberadaan panel unit root pada series yang digunakan. Pengujian stasioneritas dilakukan dengan mengunakan Levin, Lin, and Chu (LLC) Test dengan $\alpha$ sebesar $5 \%$.

Berdasarkan hasil pengujian, dapat disimpulkan dengan tingkat signifikansi 5\% terdapat cukup bukti untuk menyatakan bahwa masing-masing variabel yang diteliti telah stasioner di level.

Tabel 1 - Hasil Pengujian Unit Root di Level

\begin{tabular}{cc}
\hline Variabel & Keputusan \\
\hline FDI & Tolak $\mathrm{H}_{0}$ \\
\hline GDP & Tolak $\mathrm{H}_{0}$ \\
\hline $\mathrm{X}$ & ${\text { Tolak } \mathrm{H}_{0}}$ \\
\hline $\mathrm{M}$ & Tolak $\mathrm{H}_{0}$ \\
\hline
\end{tabular}

\subsection{Estimasi Parameter}

Berikut estimasi model dengan estimasi parameter.

$$
\widehat{F D I} I_{i t}=\widehat{\beta}_{0}+\widehat{\beta}_{1} G D P_{i t}+\widehat{\beta}_{2} X_{i t}+\widehat{\beta}_{3} M_{i t}
$$

Keterangan:

FDI: Foreign Direct Investment

GDP: Gross Domestic Product

$\mathrm{X}$ : Ekspor

M: Impor

\section{- Common Effect Model}

$$
\begin{aligned}
\widehat{F D I} I_{i t}= & -5.2461 \times 10^{9}+64249.4935 G D P_{i t} \\
& +0.0922 X_{i t}{ }^{*}-0.0798 M_{i t}{ }^{*}
\end{aligned}
$$

- Fixed Effect Model

$$
\begin{aligned}
\widehat{F D I} I_{i t}= & 1.0248 \times 10^{10}-42480.1304 G D P_{i t} \\
& +0.0626 X_{i t}-0.0588 M_{i t}
\end{aligned}
$$

- Random Effect Model

$$
\begin{aligned}
\widehat{F D I} I_{i t}= & -3.2683 \times 10^{9}-168.5503 G D P_{i t} \\
& +0.0926 X_{i t}{ }^{*}-0.0806 M_{i t}{ }^{*}
\end{aligned}
$$

Catatan: (*) signifikan pada $\alpha=0.05$

\subsection{Pemilihan Model Terbaik}

- Chow Test

$$
\begin{aligned}
& H_{0}: U_{I}=U_{2}=\ldots \ldots=U_{i}=0 ; i=1,2 \ldots \ldots, 20 \\
& H_{1}: \text { Minimal terdapat satu } U_{i} \neq 0
\end{aligned}
$$

Tabel 2 - Hasil Pengujian Chow Test

\begin{tabular}{cc}
\hline P-value & Kesimpulan \\
\hline 0.0000 & Tolak $\mathrm{H}_{0}$ \\
\hline
\end{tabular}

Dengan tingkat signifikansi 5\%, ada cukup bukti untuk menyatakan bahwa terdapat efek individu pada data panel. Untuk mendapatkan model terbaik, akan dilanjutkan Haussman Test untuk melihat efek individunya bersifat random atau fixed.

- Haussman Test

$$
\begin{gathered}
H_{0}: E\left(u_{i} \mid G D P_{i t}, X_{i t}, M_{i t}\right)=0 \\
i=1,2, \ldots, 20 ; t=1,2, \ldots, 10 \\
H_{1}: E\left(u_{i} \mid G D P_{i t}, X_{i t}, M_{i t}\right) \neq 0
\end{gathered}
$$

Tabel 3 - Hasil Pengujian Haussman Test

\begin{tabular}{cc}
\hline $\boldsymbol{P}$-value & Kesimpulan \\
\hline 0.8277 & Gagal tolak $\mathrm{H}_{0}$ \\
\hline
\end{tabular}

Dengan tingkat signifikansi 5\%, ada cukup bukti untuk menyatakan bahwa terdapat efek individu pada data panel yang bersifat random.

\section{- Interpretasi model terbaik}

Berdasarkan pengujian yang telah dilakukan, didapatkan model terbaik adalah Random Effect Model.

$$
\begin{aligned}
\widehat{F D} I_{i t}= & -3.2683 \times 10^{9}-168.5503 G D P_{i t} \\
& +0.0926 X_{i t}{ }^{*}-0.0806 M_{i t}{ }^{*}
\end{aligned}
$$

Hasil pengujian secara simultan dengan uji $\mathrm{F}$, didapatkan nilai p-value sebesar 0.0188 . Sehingga, dengan tingkat signifikansi 5\% terdapat cukup bukti bahwa variabel GDP, ekspor, dan 
impor secara bersama-sama memengaruhi FDI. Sedangkan, pengujian secara parsial dengan $\alpha=$ 5\% didapatkan hasil bahwa variabel independen yang memengaruhi FDI adalah ekspor dan impor. Secara parsial, GDP tidak memengaruhi FDI.

Variabel ekspor berpengaruh signifikan dan positif terhadap FDI. Setiap kenaikan 1 US\$ nilai ekspor, akan meningkatkan nilai FDI sebesar 0.0926 US\$ dengan asumsi variabel lain konstan. Variabel impor berpengaruh signifikan dan negatif terhadap FDI. Setiap kenaikan 1 US\$ nilai impor, akan menurunkan nilai FDI sebesar 0.0806 US\$ dengan asumsi variabel lain konstan.

\subsection{Uji Asumsi Klasik}

- Uji Normalitas

$$
\begin{aligned}
& H_{0}: \varepsilon_{i t} \sim N\left(0, \sigma_{\varepsilon}{ }^{2}\right) \\
& H_{1}: \varepsilon_{i t} \nsim N\left(0, \sigma_{\varepsilon}{ }^{2}\right)
\end{aligned}
$$

Tabel 4 - Hasil Uji Normalitas

\begin{tabular}{cc}
\hline $\boldsymbol{P}$-value & Kesimpulan \\
\hline 0.0000 & Tolak $\mathrm{H}_{0}$ \\
\hline
\end{tabular}

Dengan tingkat signifikansi 5\%, tidak terdapat cukup bukti untuk menyatakan bahwa residual data berdistribusi normal. Namun, karena jumlah data yang digunakan cukup besar maka bisa diasumsikan bahwa asumsi normalitas terpenuhi.

- Uji Autokorelasi

$$
\begin{aligned}
& H O: \rho_{\varepsilon_{t}, \varepsilon_{t-1}}=0 \\
& H 1: \rho_{\varepsilon_{t}, \varepsilon_{t-1}} \neq 0
\end{aligned}
$$

Tabel 5 - Nilai Durbin-Watson

\begin{tabular}{ccccc}
\hline $\boldsymbol{D} \boldsymbol{W}$ & $\boldsymbol{d}_{\boldsymbol{l}}$ & $\boldsymbol{d}_{\boldsymbol{u}}$ & $\mathbf{4}-\boldsymbol{d}_{\boldsymbol{l}}$ & $\boldsymbol{4}-\boldsymbol{d}_{\boldsymbol{u}}$ \\
\hline 1.8907 & 0.7176 & 1.8199 & 3.2824 & 2.1801 \\
\hline
\end{tabular}

Karena $d_{u} \leq D W \leq 4-d_{u}$, maka gagal tolak $H_{0}$. Dengan tingkat signifikansi $5 \%$, terdapat cukup bukti untuk menyatakan bahwa residual data tidak mengalami autokorelasi.

- Uji Homoskedastisitas

$$
\begin{aligned}
& H_{0}: E\left(\varepsilon_{i t}{ }^{2} \mid G D P_{i t}, X_{i t}, M_{i t}\right)=\sigma \varepsilon 2 \\
& H_{1}: E\left(\varepsilon_{i t}{ }^{2} \mid G D P_{i t}, X_{i t}, M_{i t}\right)=\sigma i t 2
\end{aligned}
$$

Tabel 6 - Hasil Uji Homoskedastisitas

\begin{tabular}{cc}
\hline $\boldsymbol{P}$-value & Kesimpulan \\
\hline 0.9479 & Gagal tolak $\mathrm{H}_{0}$ \\
\hline
\end{tabular}

Dengan tingkat signifikansi $5 \%$, tidak terdapat cukup bukti untuk menyatakan bahwa residual data bersifat homoskedastisitas.

Berdasarkan pengujian dan pendekatan yang dilakukan, maka dapat disimpulkan bahwa asumsi klasik telah terpenuhi pada model sehingga estimasi yang dilakukan pada model sudah baik dan tidak bias.

\section{Kesimpulan}

Berdasarkan pengujian yang telah dilakukan, didapatkan kesimpulan bahwa model terbaik untuk memodelkan pengaruh Gross Domestic Product (GDP), ekspor (X), impor (M) terhadap Foreign Direct Investment (FDI) pada studi kasus 20 negara dengan periode pengamatan 2009-2018 adalah Random Effect Model dengan estimator yang dihasilkan telah bersifat BLUE (Best, Linear, Unbiased Estimator).

Secara simultan, ketiga variabel independen yang digunakan berpengaruh signifikan terhadap FDI. Namun, secara parsial hanya variabel ekspor dan impor yang berpengaruh signifikan terhadap FDI. Variabel ekspor berpengaruh signifikan dan positif terhadap FDI, sedangkan variabel impor berpengaruh signifikan dan negatif terhadap FDI.

\section{DAFTAR PUSTAKA}

Albahi, Muhammad. (2016). Export-Import and Foreign Direct Investment (FDI): Indonesian Economic Study. IOSR Journal of Economics and Finance, 7(4), 37-44.

Anwar, Cep Jandi. (2016). Faktor-Faktor Yang Mempengaruhi Foreign Direct Investment (FDI) Di Kawasan Asia Tenggara. Media Trend, 11(2), 175-194.

Dunning, J.H. (1993). The Globalization of Business. London: Rouledge.

Gujarati, D. (2003). Basic Econometrics Third \& Fourth Edition. New York: McGraw-Hill.

Naseem et al. (2011). Impact of Foreign Direct Investment on Gross Domestic Product. Global Journal of Management and Business Research, 11(8), 35-40.

Prabhakar, Akhilesh Chandra. (2015). Foreign Direct Investment, Trade and Economic Growth: A New 
Paradigm of the BRICS. Modern Applied Science, 9(12), 32-42.

Purba, Putri S. (2015). Pengaruh Impor Dan Nilai Tukar Terhadap Investasi Langsung Asing Di Indonesia. Jurnal Administrasi Bisnis, 28(1), 4349.

Salvatore, D. (2007). International Economics. New Jersey: Prentice-Hall.

Salvatore, D. (2014). Ekonomi Internasional. Jakarta: Salemba Empat.

Todaro, M.P dan Smith, S.C. (2003). Pembangunan Ekonomi di Dunia Ketiga Jilid I. Jakarta: Penerbit Erlangga.

Winardi. (1992). Kamus Ekonomi. Bandung: Mandar Maju. 